\title{
Sarcoma sinovial da articulação antebraquiocárpica em cão
}

\section{Antebrachiocarpal joint synovial sarcoma in a dog}

\section{Sarcoma sinovial de la articulación antebraquiocarpiana en perros}

\section{Ana Carolina Brandão de Campos Fonseca Pinto;' Angélica Cecilia Tatarunas; ${ }^{2}$ Maria Carolina Catai Chalita; ${ }^{3}$ Nilceo Schwery Michalany; ${ }^{4}$ Julia Maria Matera ${ }^{5}$}

Departamento de Cirurgia da Faculdade de Medicina Veterinária da Universidade de São Paulo (FMVZ/USP). São Paulo, SP, Brasil

\section{Resumo}

Objetivo: Descrever sinais clínicos, diagnóstico citológico, radiográfico e histopatológico de um cão portador de sarcoma sinovial na articulação antebraquiocárpica. A literatura foi pesquisada nas bases de dados CAB e MEDLINE, pelo período retrospectivo de 48 anos. Descrição: Um cão, macho inteiro, sem raça definida, nove anos de idade, foi atendido no Serviço de Cirurgia de Pequenos Animais do Hospital Veterinário da Faculdade de Medicina Veterinária e Zootecnia da Universidade de São Paulo, São Paulo, SP, apresentando neoformação subcutânea em região cranial à articulação antebraquiocárpica direita. Os estudos radiográfico e citológico sugeriram processo neoplásico de comportamento maligno e a análise histopatológica confirmou o diagnóstico de sarcoma sinovial. Instituído tratamento cirúrgico com amputação proximal do membro acometido, a sobrevida foi de sete meses. Conclusões: O sarcoma sinovial é uma neoplasia maligna agressiva e que pode mimetizar uma neoformação subcutânea, portanto, deve-se atentar para sua presença a fim de intervir de forma precoce e por meio do seu reconhecimento obter melhores resultados.

Palavras-chave: Neoplasias. Sarcoma sinovial, diagnóstico. Artrografia. Articulações, cirurgia. Amputação. Cães. 


\section{Sarcoma sinovial da articulação antebraquiocárpica em cão}

\section{Antebrachiocarpal joint synovial sarcoma in a dog}

\section{Sarcoma sinovial de la articulación antebraquiocarpiana en perros}

\section{Ana Carolina Brandão de Campos Fonseca Pinto;' Angélica Cecilia Tatarunas; ${ }^{2}$ Maria Carolina Catai Chalita; ${ }^{3}$ Nilceo Schwery Michalany; ${ }^{4}$ Julia Maria Matera ${ }^{5}$}

Departamento de Cirurgia da Faculdade de Medicina Veterinária da Universidade de São Paulo (FMVZ/USP). São Paulo, SP, Brasil

\section{Resumo}

Objetivo: Descrever sinais clínicos, diagnóstico citológico, radiográfico e histopatológico de um cão portador de sarcoma sinovial na articulação antebraquiocárpica. A literatura foi pesquisada nas bases de dados CAB e MEDLINE, pelo período retrospectivo de 48 anos. Descrição: Um cão, macho inteiro, sem raça definida, nove anos de idade, foi atendido no Serviço de Cirurgia de Pequenos Animais do Hospital Veterinário da Faculdade de Medicina Veterinária e Zootecnia da Universidade de São Paulo, São Paulo, SP, apresentando neoformação subcutânea em região cranial à articulação antebraquiocárpica direita. Os estudos radiográfico e citológico sugeriram processo neoplásico de comportamento maligno e a análise histopatológica confirmou o diagnóstico de sarcoma sinovial. Instituído tratamento cirúrgico com amputação proximal do membro acometido, a sobrevida foi de sete meses. Conclusões: O sarcoma sinovial é uma neoplasia maligna agressiva e que pode mimetizar uma neoformação subcutânea, portanto, deve-se atentar para sua presença a fim de intervir de forma precoce e por meio do seu reconhecimento obter melhores resultados.

Palavras-chave: Neoplasias. Sarcoma sinovial, diagnóstico. Artrografia. Articulações, cirurgia. Amputação. Cães.

'Professora Doutora do Departamento de Cirurgia FMVZ/USP. CRMV-SP 8465

${ }^{2}$ Pós-Doutoranda do Departamento de Cirurgia da FMVZ/USP. CRMV-SP 5751

${ }^{3}$ Médica Veterinária. Mestre pela FMVZ/USP. CRMV-SP 6710

${ }^{4}$ Professor Associado Doutor do Departamento de Anatomia Patológica da Escola Paulista de Medicina da Universidade Federal de São Paulo

${ }^{5}$ Professora Titular do Departamento de Cirurgia da FMVZ/USP. CRMV-SP 1050 


\section{Introdução e Revisão de Literatura}

O sarcoma sinovial (SS), descrito pela primeira vez em 1956 por Lieberman', é considerado um tumor maligno de origem mesenquimal de ocorrência incomum em cães. ${ }^{2,3,4,5}$ É também denominado de sarcoma de células sinoviais, sinovioma, carcinossarcoma sinovial e sinovioma maligno. ${ }^{3,4,5,6,7,8}$ Essa neoplasia manifesta-se principalmente em cães de médio a grande portes, não havendo predisposição racial e entre sete e oito anos de idade, $3,4,5,7,9$ porém raças de pequeno porte $\mathrm{e}$ animais jovens também são descritos. ${ }^{10} \mathrm{O}$ joelho e o cotovelo são as articulações mais acometidas, todavia, a articulação do ombro, antebraquiocárpica, talocrural, $3,3,6,7,7,11,12,13$ coxofemoral $^{2}$, interfalangeana ${ }^{4}$, têmporo mandibular, ${ }^{14}$ metacarpofalangeana e apófise de vértebra cervical ${ }^{15}$ e lombar ${ }^{9}$ são relatadas. Sinais clínicos geralmente consistem em claudicação e presença de formação localizada junto a uma articulação ou tendão em um dos membros, bem como sensibilidade local e diminuição na amplitude de movimento. ${ }^{3,4,8,9}$

Ao exame radiográfico, o SS pode inicialmente apresentar-se como um aumento de partes moles sem evidência de comprometimento ósseo, ou envolvimento ósseo predominantemente lítico, com destruição da cortical e acometendo ambas as extremidades dos ossos que compõem a articulação. Proliferação periosteal e mineralização de partes moles também são observadas. ${ }^{3,4,5,9,11,15}$

Histologicamente o SS caracteriza-se pela presença de células mesenquimais; sinoviócito tipo $\mathrm{A}$, que se origina da medula óssea e migra para a articulação; e tipo B, o qual compreende $70 \%$ a $80 \%$ das células sinoviais e possui características ultraestruturais de fibroblasto. ${ }^{15}$

No homem, diferente do cão, acredita-se que o sarcoma sinovial não se origine de células do revestimento sinovial, de acordo com estudo ultra-estrutural e imunoistoquímico realizado por Miettinen e Virtanen ${ }^{16}(1984)$ e Salisbury e Isaacson, ${ }^{17}$ respectiva- mente. Patologistas classificam o SS no homem como bifásico, monofásico fibroblástico, monofásico epitelióide e pobremente diferenciado, haja vista que dois elementos celulares, fibroblástico e epitelióide podem estar presentes em diferentes proporções. Em estudos realizados na espécie canina, Vail et al. ${ }^{4}$ (1994) relatam seis tumores monofásicos e 30 bifásicos, e Fox et al. ${ }^{9}$ (2002), 75\% de tumores bifásicos, quando do uso da classificação histológica do SS humano.

São considerados fatores de prognóstico para o tempo de sobrevida e intervalo livre de doença do SS no cão: índice mitótico, porcentagem de necrose tumoral e grau de pleomorfismo nuclear. ${ }^{4}$ Também o sistema de estagiamento clínico (TNM) da Organização Mundial de Saúde (OMS) e a coloração imunoistoquímica positiva para citoqueratina têm implicação prognóstica. ${ }^{9}$

Para o tratamento do tumor a exérese local e a amputação do membro, associadas ou não com radioterapia ou quimioterapia, são descritas na literatura com resultados variados. ${ }^{4,8,9}$

Os sítios mais comuns de metástase são os pulmões e os linfonodos, porém rins, baço, pleura torácica, figado, coração e pele também são relatados. ${ }^{8}$ Vail et al. ${ }^{4}$ (1994) e Fox et al. ${ }^{9}$ (2002) citam $22 \%$ e $8 \%$, respectivamente, de evidência de metástase no momento do diagnóstico em cães com SS.

O presente trabalho tem por objetivo relatar a evolução, os diagnósticos clínico, radiográfico, citológico e histopatológico e o tratamento do sarcoma sinovial de articulação antebraquiocárpica em um cão.

\section{Relato de Caso}

Um cão, macho inteiro, sem raça definida, nove anos de idade e pesando $20 \mathrm{~kg}$ foi atendido no Serviço de Cirurgia de Pequenos Animais do Hospital Veterinário da Faculdade de Medicina Veterinária e Zootecnia da Universidade de São Paulo, São Paulo, SP, apresentando neoformação subcutânea em 
região cranial à articulação antebraquiocárpica direita de quatro meses de evolução e crescimento lento. A formação média $-4 \mathrm{~cm}$ de comprimento, $2,5 \mathrm{~cm}$ de largura e $1 \mathrm{~cm}$ de altura - apresentava os seus limites pouco definidos, consistência macia, nãoulcerada, parcialmente aderida a planos profundos e sensível a dígito pressão (Figura 1). Os linfonodos axilar e pré-escapular apresentavam-se com dimensões normais quando comparados aos contralaterais.

Um primeiro estudo radiográfico da articulação antebraquiocárpica denotou comprometimento articular com áreas de osteólise nos ossos do carpo, mais evidentes nos ossos acessórios do carpo, carpo ulnar e carpo radial, e em terços distais de rádio e ulna direitos (Figura 2). O controle radiográfico realizado 30 dias depois mostrou acentuado aumento das áreas de lise óssea ratificando evolução desfavorável do quadro (Figura 3).

A citologia da formação, realizada após o primeiro estudo radiográfico, demonstrou presença de grande quantidade de células pequenas com citoplasma levemente fusiforme, dispostas isoladamente em sua maioria. Além disso, uma discreta anisocariose, pouca variação no padrão de condensação da cromatina, nucléolos pouco visíveis e pequenos, e foram observadas algumas figuras de mitose atípicas, achados esses sugestivos de neoplasia bem diferenciada de origem mesenquimal.

Foi realizada a amputação proximal do membro com exérese do linfonodo axilar. Exames complementares (hemograma, plaquetas, bioquímica sérica) apresentavam-se dentro dos limites da normalidade.

O exame histopatológico mostrou tecido conjuntivo fibrilar denso de região justa articular apresentando neoplasia mesenquimal maligna com áreas sólidas constituídas por células com núcleos ovóides ou alongados e com citoplasma eosinófilo, com múltiplas áreas de necrose de coagulação, tendo de permeio estruturas cavitárias revestidas internamente por células epiteliais colunares. Em outros trechos, a neoplasia formava estruturas císticas revestidas internamente por epitélio colunar com presença de células fusiformes atípicas nos septos (Figura 4). A neoplasia apresentava discreta atividade mitótica e discreto grau de polimorfismo nuclear e hipercromasia, sendo, porém, freqüentes as áreas de necrose de coagulação. $\mathrm{O}$ diagnóstico histopatológico da lesão foi compatível com sarcoma sinovial. O paciente veio a óbito cerca de sete meses após o procedimento cirúrgico, quando apresentou metástase em campos pulmonares.

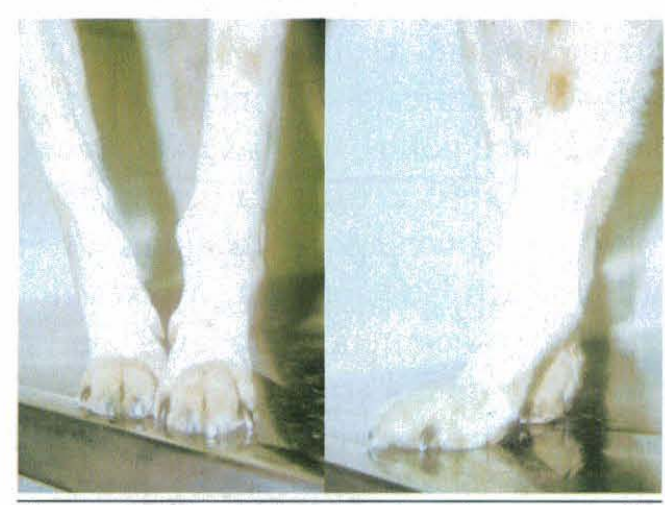

Figura 1 - Neoformação subcutânea em região região cranial à articulação antebraquiocárpica

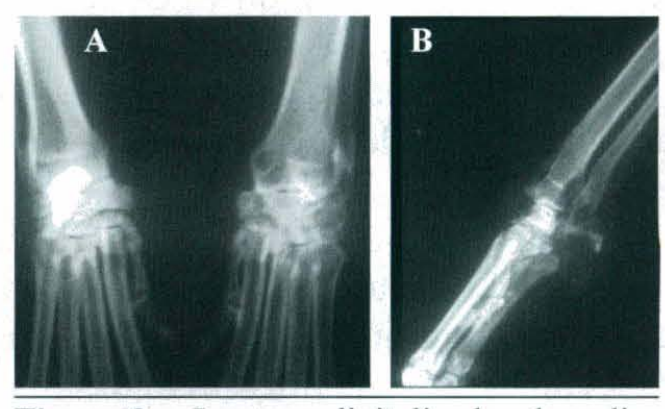

Figura 2 - Imagens digitalizadas de radiografias em projeções (A) dorso-palmar e (B) médio-lateral em que se observam áreas de osteólise nos ossos do carpo e em terços distais de rádio e ulna direitos

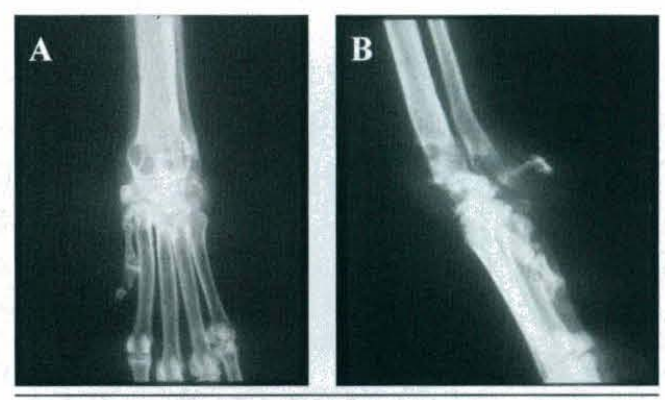

Figura 3 - Imagens digitalizadas de radiografias em projeções (A) dorso-palmar e (B) médiolateral em que se observa evolução desfavorável do quadro em relação ao exame radiográfico anterior, com aumento das áreas de lise (Figura 2) 


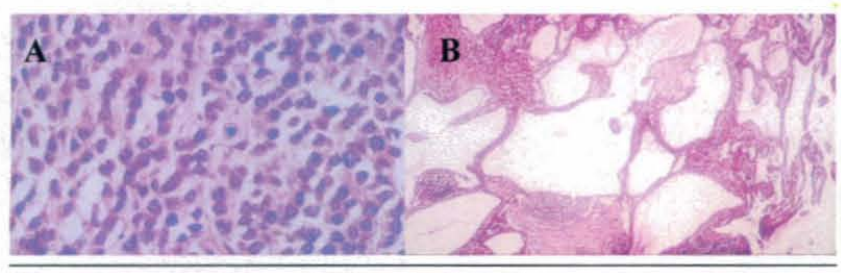

Figura 4 - Em fotomicrografia (A) observam-se células com núcleos ovóides ou alongados e com citoplasma eosinofilico e, em (B), estruturas císticas revestidas internamente por epitélio colunar com presença de células fusiformes atípicas nos septos. H\&E

\section{Discussão}

O SS sinovial é um tumor que geralmente acomete cães de meia idade, portes médio a grande, e não há predisposição racial. Cães sem raça definida também são citados na literatura, ${ }^{3,4,5,9}$ confirmando os dados observados no presente estudo.

A articulação antebraquiocárpica, apesar de descrita anteriormente ${ }^{4}$; não é comumente afetada pela neoplasia. Os sinais clínicos e radiográficos apresentaram-se de acordo com a literatura consultada. $3,4,5,7,9,11,14$ Contudo, cabe ressaltar a aparência inicial do sarcoma sinovial como um tumor de tecidos moles, o que foi observado no animal deste relato.

A citologia, como sugerido por McGlennon et al. ${ }^{8}$ (1988) pode revelar a presença de células neoplásicas com características de malignidade, porém, o resultado final do sarcoma sinovial deve ser confirmado por exame histopatológico, o que foi realizado no animal do presente relato.

Dentre as formas de tratamento preconizadas pelos autores, a amputação do membro acometido é de eleição na maioria das vezes, haja vista que a exérese local geralmente está associada com recidiva do tumor $^{8,11}$ e: apesar de o SS poder manifestar-se lentamente quanto aos sinais clínicos e ter baixo índice mitótico, deve ser tratado como um tumor maligno agressivo. ${ }^{2,8}$ Fox et al. ${ }^{9}$ (2002) afirmam que em seu estudo a forma de tratamento foi o fator determinante da sobrevida dos cães com sarcoma sinovial.
A sobrevida entre os cães portadores de SS e que foram amputados variou de seis meses $^{8,13}$ a mais de dois anos ${ }^{8}$. Vail et al. ${ }^{4}$ (1994) citam recorrência no coto amputado três meses e meio a seis, após a cirurgia e desenvolvimento de metástase no período de um a 12 meses. O cão estudado esta dentro do intervalo de tempo de sobrevida citado na literatura.

A origem do SS, bem como a sua classificação histológica é contraditória entre os autores consultados. Enquanto Madewell e Pool ${ }^{6}$ (1978); Vail et al. $^{4}$ (1994); Fox et al. ${ }^{9}$ (2002) sugerem o uso da classificação utilizada no homem para este tumor, Pool e Thompson ${ }^{15}$ (2002) são contrários a essa conduta, pois, para eles, enquanto na espécie canina o SS possui características microscópicas que suportam uma origem sinovial, no homem isso não ocorre e, portanto, parece haver pouca justificativa para se classificar o SS nos animais de acordo com critérios usados em medicina humana. Segundo eles, ainda, em animais o SS pode ser análogo ao sarcoma sinovial monofásico de pacientes humanos em que células fusiformes predominam e o elemento epitelial é ausente ou pobremente desenvolvido. ${ }^{18,19}$ Apesar de não se ter classificado histologicamente a neoplasia estudada como sugerido por Pool e Thompson, ${ }^{15}$ acredita-se que esse seja um tópico que ainda carece de estudo.

Fox et al. ${ }^{9}$ (2002) afirmam que embora o SS seja incomum, a sua incidência tem aumentado nos últimos anos, talvez devido ao seu maior reconhecimento, já que o seu diagnóstico muitas vezes é difícil. Portanto, deve-se atentar para sua presença nos pacientes a fim de se poder intervir de forma precoce e, por meio do seu reconhecimento, obter melhores resultados.

\section{Agradecimentos}

Os autores agradecem a Dra. Adriane Provasi, ao Prof. Dr. Masao Iwasaki e ao Prof. Dr. Franklịn de Almeida Sterman pela colaboração na divulgação do presente relato. 
PINTO, A. C. B. C. et al. Sarcoma sinovial da articulação antebraquiocárpica em cão. / Antebrachiocarpal joint synovial sarcoma in a dog. / Sarcoma sinovial de la articulación antebraquiocarpiana en perros. Rev. Educ. Contin. CRMV-SP/Contin. Educ. J. CRMV-SP, São Paulo, v. 7, n. $1 / 3$, p. $34-39,2004$.

\section{Abstract}

Objective: To describe the clinical signs and radiographic, cytological and histopathological findings in a dog presented with antebrachiocarpal joint synovial sarcoma. The literature search was performed in CAB and MEDLINE databases, for the retrospective period of 48 years. Description: A 9 year-old mongrel intact male dog was presented to the Small Animal Surgery Service of the Veterinary Hospital of the School of Veterinary Medicine and Animal Science of the University of São Paulo, São Paulo, SP,Brazil, for evaluation of a subcutaneous soft tissue mass located cranial to the right antebrachiocarpal joint. Radiographic and cytological findings suggested a malignant neoplasm, which was confirmed by the histopathological analysis to be a synovial sarcoma. The dog lived for 7 months following high amputation of the affected limb. Conclusions: Synovial sarcoma is an aggressive malignant neoplasm that can present as a soft tissue mass. Such features should be carefully noted, as early diagnosis and intervention will enable better results.

Keywords: Neoplasms. Sarcoma, synovial, diagnosis. Arthrography. Joints, surgery. Amputation. Dogs.

\section{Resumen}

Objetivo: Describir las señales clínicas, los diagnósticos citológico, radiográfico e histopatológico de un perro con sarcoma sinovial en la articulación antebraquiocarpiana. La literatura se obtuvo de las bases de datos de CAB y MEDLINE, durante un periodo retrospectivo de 48 años. Descripción: Un perro, macho, no castrado, sin raza definida y de 9 años de edad, fue atendido en el Servicio de Cirugía de Pequeños Animales del Hospital Veterinario de la Facultad de Medicina Veterinaria y Zootecnia de la Universidad de São Paulo, São Paulo, SP, Brasil. Presentó neoformación subcutánea en región craneal a la articulación antebraquiocarpiana derecha.Los estudios radiográfico y citológico sugirieron proceso neoplásico de comportamiento maligno, y el análisis histopatológico confirmó el diagnóstico de sarcoma sinovial.Al animal se le amputó su miembro torácico y sobrevivió durante 7 meses. Conclusiones: El sarcoma sinovial es un neoplasma maligno agresivo, y puede mimetizar una neoformación subcutánea. Por tanto, se debe prestar atención a su aparición para intervenir de modo precoz y así a través de su reconocimiento obtener mejores resultados.

Palabras-clave: Neoplasmas. Sarcoma sinovial, diagnóstico. Artrografía. Articulaciones, cirugía. Amputación. Perros.

\section{Referências}

1. LIEBERMAN, L. L. Synovioma of a dog. Journal of the American Veterinary Medical Association, v. 128 , p. $263-264,1956$.

2. KARAYANNOPOULOU, M.; KALDRIMIDOU, E.; DESSIRIS, A. Synovial sarcoma in a dog. Journal of Veterinary Medicine, v. 39, p. 76-80, 1992.
3. WATERS, D. J. Musculoskeletal system. In: SLATTER, D. Textbook of small animal surgery. 2. ed. Philadelphia: Saunders, 1993. p. 2213-2230.

4. VAIL; D. M. et al. Evaluation of prognostic factors for dogs with synovial sarcoma: 36 cases (19861991). Journal of the American Veterinary Medical Association, v. 205, p. 1300-1307, 1994. 
5. GRAEME, A. Radiographic signs of joint disease. In: THRALL, D. E. Textbook of veterinary diagnostic radiology. 3. ed. Philadelphia: Saunders, 1998. p.169-188.

6. MADEWELL, B. R.; POOL, R. Neoplasms of joints and related structures. Veterinary Clinics of North America: Small Animal Practice, v. 8, p. 511-521, 1978.

7. LIPOWITZ, A. J.; FETTER, A. W.; WALKER, M. A. Synovial sarcoma of the dog. Journal of the American Veterinary Medical Association, v. 174, p. 76-81, 1979.

8. McGlenNON, N. J.; HOUlton, J. E. F.; GORMAN, N. T. Synovial sarcoma in the dog: a review. Journal of Small Animal Practice, v. 29, p. $139-152,1988$.

9. FOX, D. B. et al. Canine sinovial sarcoma: a retrospective assessment of described prognostic criteria in 16 cases (1994-1999). Journal of the American Animal Hospital Association, v. 38, p. 347-355, 2002.

10. BELLAH, J. R.; PATTON, C. S. Nonweightbearing lameness secondary to synovial sarcoma in a young dog. Journal of the American Veterinary Medical Association, v. 188, p. 730-732, 1986.

11. MITCHELL, M.; HUROV, L. I. Synovial sarcoma in a dog. Journal of the American Veterinary Medical Association, v. 175, p. 53-55, 1979.
12. POOL, R. R. Joints and adjacent soft tissues. In: MOUltON, J. E. Tumors in domestic animals. 3. ed. Los Angeles: University of California Press, 1990. p. 133-143.

13. WHITELOCK, R. G. et al. A review of 30 tumors affecting joints. Veterinary Comparative Orthopedics Traumatology, v. 10, p.146-152, 1997.

14. GRIFFITH, J. W.; FREY, R. A.; SHARKEY, F. E. Synovial sarcoma of the jaw in a dog. Journal of Comparative Pathology, v. 97, p. 361-364, 1987.

15. POOL, R. R.; THOMPSON, K. G. Malignant tumors and tumor-like lesions in and around joints, tendons, and deep fasciae. In: MEUTEN, D. J. Tumors in domestic animals. 4. ed. Ames: Iowa State Press, 2002. p. 199-244.

16. MiETTINEN, M.; VIRTANEN, I. Synovial sarcoma: a misnomer. American Journal of Pathology, v. 117, p. 18-25, 1984.

17. SALISBURY, J. R.; ISAACSON, P. G. Synovial sarcoma: an immunohistochemical study. Journal of Pathology, v. 147, p. 49-57, 1985.

18. DICKERSIN, G. R. Synovial sarcoma: a review and update, with emphasis on the ultrastructural characterization of the nonglandular component. Ultrastructural Patholology, v. 15, p. 379-402, 1991.

19. FOX, R. I.; KANG, H. Structure and function of synoviocytes. In: McCARTY, D. Arthritis and allied conditions: a textbook of rheumatology. 12. ed. Philadelphia: Lea and Febiger, 1993. p.263. 